\title{
The Assessment Of Market Risk Premium In South Africa
}

\author{
Lumengo Bonga-Bonga, University of Johannesburg, South Africa
}

\begin{abstract}
This paper makes use of time-varying parameter GARCH-M model to estimate the risk aversion parameter for the South African stock market. The paper further compares the forecasts performance of a time-varying risk premium model with that of a constant risk premium model in predicting stock market returns on the South African stock exchange. The findings of the paper show that risk premium is time varying and indicate that stock market in South Africa is vulnerable to external shocks. Moreover, the paper finds that the time-varying GARCH-M model outperforms the fixed parameter GARCH-M model in predicting stock returns when short-term forecast horizons are used.
\end{abstract}

Keywords: Risk premium, time varying GARCH, predictability of stock returns

\section{INTRODUCTION}

¿

nvestors' preference for risk is central to investment decisions. Risk and return appear to be the important elements that need to be taken into account in investment decisions. Moreover, given the fact that many economic and financial theories support the view that investors are risk averse, this should imply that investors will demand a high compensation or risk premium, in terms of a higher expected return, for taking a specific risk.

The risk-return trade-off model is widely used in finance, particularly in the context of the capital asset pricing model (CAPM).The CAPM postulates a linear relationship between an asset's beta (a measure of systematic risk) and expected returns (Sharpe, 1964; Bodie and Merton, 2000). In addition, Merton (1973) estimated a variant of the traditional CAPM known as the Intertemporal Capital Asset Pricing Model (ICAPM) Like the CAPM the ICAPM implies a positive, linear relationship between the aggregate market return and the risk premium of the market. Nonetheless, contrary to the CAPM, the ICAPM allows additional risk factors besides the market variance to explain asset returns.

Both the CAPM and the ICAPM assume that investors will demand a higher risk premium for the same level of risk if they become more risk averse over time. Conversely, if investors become less risk averse they will demand less risk premium per unit of risk and, consequently, the market price of risk (defined as the risk premium per unit of variance risk) will decrease over time (Ahn and Shrestha, 2009). This implies that investors will often change their perception on the degree of risk attached to a specific investment opportunity. Thus, the assessment of risk aversion and the degree of risk premium of investors will be time varying.

A number of studies that undertook empirical tests using the original ICAPM found that the coefficient of risk aversion is constant through time (Chen, 2003; Guo, 2006; Merton 1980). However, in the literature on habit formation there are also a number of studies that use ICAPM to show that the relative risk aversion is time varying. For example, $\mathrm{Li}$ and Zhong (2005) indicate that a negative shock to consumption pushes the representative agent closer to the habit level, consequently increasing risk aversion and the required return on risky assets. This indicates that time-varying risk aversion is a critical element in the determination of the price of risks and returns on specific assets. 
Compared to developed economies, emerging market economies are subject to changes in the price of risk due to their high sensitivity to global financial crises. For example, Frank and Hesse (2009) show that the increase in global risk aversion among investors, arising from problems in developed economies, rapidly spilled over into emerging market economies. This occurs as investors choose to pull out of emerging financial markets to relocate their investment in the financial markets of developed economies, as these financial markets are perceived to be safer than those of emerging economies. This indicates that the change in the magnitude of risk aversion in emerging market economies depends on factors that are both internal and external to those economies. Investors who are willing to allocate funds to emerging financial markets during periods of financial crisis will certainly ask for higher return to compensate for the increased risk level. All of these factors should support the hypothesis that the price of risk continually changes in emerging market economies.

In addition, a number of authors attribute the vulnerability of emerging markets to global risk aversion shocks to the increasing degree of financial integration. For example, Grabel (2003) shows that the severity of the contagion risk in emerging economies depends on the degree of financial openness and the extent to which emerging market countries have measures in place that constraint currency and contagion risks. Moreover, Bonga-Bonga (2009) uses the covered interest parity measures to determine the extent of South Africa's integration into the global financial market. The author finds that South Africa is becoming progressively more integrated into the world financial market. The increasing degree of South African integration into the global financial market should indicate the vulnerability of its economy to global risk aversion. This factor should strongly influence the changing nature of its risk assessment and, thus, contribute to the time-varying market risk premium in South Africa.

A number of studies have attempted to measure the changing nature of market risk premiums. These studies rely on the framework suggested by Merton $(1973,1980)$ in providing the measurement of relative risk aversion. Merton's (1973) ICAPM shows that the conditional expected excess return on aggregate market portfolio will be proportional to the conditional variance of this return, where the constant of proportionality depends on the risk aversion of the representative agent. Thus, within the ICAPM framework the coefficient of variance or standard deviation in the conditional mean equation is interpreted as the coefficient of relative risk aversion (Merton, 1980). A number of authors have used different methodologies, mainly based on single-factor analysis, to establish the time-varying nature of the coefficient of relative risk aversion. Kim and Lee (2008) use an asymmetric generalised autoregressive conditional heteroscedasticity in mean (AGARCH) model and a Markov switching model to show that investors become more risk averse during boom periods. Ahn and Shrestha (2009) estimated the risk aversion parameter for the Japanese stock market using the Time Varying Parameter (TVP) GARCH-M model and found that the risk aversion parameter has changed in the range between 2.2 and 3.5 for the Japanese stock market. Das and Sarkar (2009) propose an information matrix (IM)-based test for assessing the hypothesis of constant relative risk aversion parameters in the GARCH-M set-up. The proposed test has been applied on return data from five major stock price indices, namely the S\&P-500 composite index (USA), the FTSE-100 (UK), Topix (Japan), the HangSeng (Hong Kong) and the DAX (Germany). The authors find that the null hypothesis of constant relative risk aversion is rejected for all five stock price indices. This lends support to the hypothesis that there is time-varying risk aversion in these exchange markets.

Based on a single-factor model, this paper makes use of the time-varying parameter GARCH-M model to estimate the risk aversion parameter for the South African stock market as in Ahn and Shrestha (2009). However, this paper differs from previous studies that estimate the risk aversion parameter in that it further compares the forecast performance of a time-varying risk premium model with that of a constant risk premium model in predicting stock market returns on the South African stock exchange, the Johannesburg Stock Exchange (JSE).

The paper is organised as follows. In section 2 the methodology and empirical results are presented. Section 3 discusses the forecast performance of the models and section 4 concludes the paper.

\section{METHODOLOGY}

Merton's (1973) ICAPM provides the background for the measurement for the relative risk aversion. In this model, the coefficient of variance or standard deviation in the conditional mean equation is interpreted as the coefficient of relative risk aversion. 
The ICAPM implies the following equilibrium relationship between expected return and risk for any risky asset:

$$
\mu_{i}-r_{f}=\alpha+\beta \sigma_{i m}+\delta \sigma_{i x}
$$

where $r_{f}$ is the risk-free interest rate, $\mu_{i}-r_{f}$ is the expected excess return on the risky asset $i, \sigma_{i m}$ denotes the covariance between the excess returns on asset $i$ and the market portfolio $m$, and $\sigma_{i x}$ denotes the covariance between the excess return on the risky asset $i$ and the $n$ state variables $x . \sigma_{i x}$ is also known as the hedge component.

In the framework represented in Equation (1), the coefficient $\beta$ represents the relative risk aversion and $\delta$ measures the market aggregate reaction to changes in $n$-dimensional state variables that control the stochastic investment opportunity set. Given the difficulty in identifying the total number of state variables potentially of hedging concern to investors (Fama, 1998), a number of empirical time series studies that aim at estimating the risk aversion coefficient assume that the hedging demand component $\left(\sigma_{i x}\right)$ is equal to zero. Thus, Equation (1) is reduced to:

$\mu_{i}-r_{f}=\alpha+\beta \sigma_{i m}$

In the original ICAPM of Merton (1973), the relative risk aversion coefficient $\beta$ is assumed to be positive and statistically significant, implying a positive risk-return trade-off. Moreover, another implication of the original ICAPM is that the intercept $\alpha$ should not be different from zero assuming that the covariance of risky assets with market portfolio has enough power to predict excess returns (Bali and Engle, 2007).

If the equilibrium relation in Equation (1) is applied to a market portfolio, assuming the absence of a hedging demand component, the risk-return relation is represented as:

$\mu_{m}-r_{f}=\alpha+\beta \sigma_{m}^{2}$

where $\sigma_{m}^{2}$ is the variance of the market portfolio.

Different empirical methods are used to estimate the coefficient of relative risk aversion with the aid of Equation (3). The most common method is the Generalised Autoregressive Conditional Heteroscedasticity in Mean (GARCH-M) model of Engle, Lilien and Robins (1987). The popularity of this model is due to its ability to model the risk-return trade-off while taking into account the time-varying volatility that characterises returns series. Nonetheless, a number of these models make use of the assumption of constant coefficients in the mean and volatility equations of the GARCH-M process (French, Schwert and Stambaugh, 1987; Chou, 1988).

This paper contends that a number of internal and external factors, such as the increasing degree of integration of the South African financial market into the world economy, can make South Africa vulnerable to global risk aversion shocks and cause the coefficient of market risk aversion to be time varying. Thus, this paper estimates the time-varying market risk aversion by making use of the Kalman filter algorithm in modelling the riskreturn relationship within the context of the GARCH-M process.

Given the fact that a number of empirical studies support the use of an AR(1)-GARCH (1,1)-M process for modelling stock returns in emerging stock markets (Abdmoulah, 2010; Shin, 2005; Salman, 2002; Zalewska-Mitura and Hall, 1999), this paper estimates the time-varying risk aversion from the following equations: 


$$
\begin{aligned}
& \mu_{t}=\alpha_{1} \mu_{t-1}+\beta_{t} \sigma_{t}^{2}+e_{t}, e_{t} \sim N\left(0, \sigma_{t}^{2}\right) \\
& \sigma_{t}^{2}=\phi_{0}+\phi_{1} \varepsilon_{t-1}^{2}+\phi_{2} \sigma_{t-1}^{2} \\
& \beta_{t}=\beta_{t-1}+v_{t}, v_{t} \sim\left(0, \sigma^{2}\right)
\end{aligned}
$$

where $\mu_{t}$ represents the market portfolio nominal return and $\beta_{t}$ represents the time-varying risk aversion coefficient. It is worth noting that a number of studies hold that the risk-return relationship can be assessed by modelling the relationship between stock return and volatility rather than excess stock return and its volatility as in the CAPM framework (Jagannathan and Runkle, 1993; Chan, et al., 1992).

This model is estimated using the standard Kalman filter, where Expression (4) represents the signal or measurement equation and Expressions (5) and (6) represent the state equations. The maximum likelihood function is used to estimate the time-paths of $\beta_{t}$ as well as all coefficients in the measurement and state equations. $\beta_{t}$ is modelled as a random walk process.

It is important to note that the Kalman filter is a recursive procedure for computing the optimal estimator of the state vector at time $t$, based on information available at the same time (Harvey, 1989:104). The Kalman filter estimation problem can be set into state-space form by defining the state vector represented by a certain parameter. The equations representing the state vectors, such as Equations 5 and 6, are known as transition equations. The state vectors are not observed directly; instead the state of the system is conveyed by an observed variable, represented here by Equation 4, called a signal equation, which is subject to contamination by disturbance or measurement error. The equation representing an observable variable is also known as a measurement equation.

A general example of the state-space model underlying the Kalman filter can be represented as follows:

$$
Y_{t}=H_{t} \xi_{t}+\eta_{t}
$$

This equation represents the observation, signal or measurement equation. The transition or state equation is expressed as:

$$
\xi_{t}=\Phi_{t} \xi_{t-1}+v_{t}
$$

$Y_{t}$ is the observation on the system, $H_{t}$ is the vector of regressors and $\xi_{t}$ is the state vector. The random variables $\eta_{t}$ and $v_{t}$ represent the measurement and state disturbance or noise respectively. They are assumed to be independent of each other and white noise, and with a normal probability distribution, meaning that:

$\mathrm{p}(\eta) \approx \mathrm{N}(0, \mathrm{Q})$

and

$\mathrm{p}(U) \approx \mathrm{N}(0, \mathrm{R})$

$\mathrm{p}(\eta)$ and $\mathrm{p}(U)$ stand for the probability distribution of the errors $\eta$ and $U$ respectively and $\mathrm{Q}$ is the covariance of the measurement, while $\mathrm{R}$ is the covariance of the state noise.

Because of its recursive character, the estimation of the equations of the Kalman filter requires the determination of the initial estimate of the state vector $\xi_{0}$ at time $t=0$ and of its variance matrix. It is assumed that 
$\mathrm{H}_{\mathrm{t}}, \Phi_{t}, \mathrm{Q}$ and $\mathrm{R}$ are known for all $\mathrm{t}=1, \ldots . \mathrm{n}$, the same as the initial estimate for the state vector and its variance matrix. With a set of information at time t given as $I_{t}=\left\{Y_{1}, \ldots, Y_{t}\right\}$ and given the initial estimate, for example $\mathrm{x}_{0}$, for the state vector $\xi_{0}$, the Kalman filter equation determines the state vector estimates:

$$
X_{t / t-1}=E\left(\xi_{t} / I_{t-1}\right)
$$

And

$$
X_{t}=E\left(\xi_{t} / I_{t}\right)
$$

and their associated variance matrices.

In order to estimate time-varying risk aversion with the aid of the AR(1)-GARCH(1,1)-M model, this paper makes use of the time series of returns on the Johannesburg Securities Exchange All-Share Index (JSE-Alsi), referred to as RET. The JSE-Alsi, as a stock market index, represents the performance of the largest companies (approximately 80\% of market capitalisation) listed on the JSE. Weekly data from March 1995 to February 2010 is used to estimate the time-varying risk aversion. The starting sample period corresponds with the liberalisation of the JSE. In fact, in an effort to stimulate economic growth, the South African government lifted all controls on nonresident investors in March 1995, allowing liberalisation of the stock exchange in South Africa and its integration into the global financial market (Tswamuno et al, 2007). Moreover, Bonga-Bonga (2009) shows that the liberalisation of the JSE in March 1995 coincides with the increasing financial integration of South Africa into the global financial market.

Figure 1 represents the evolution of the JSE-Alsi returns (RET). It is clear from the figure that the return series displays conditional volatility whereby highly volatile periods are interspersed with tranquil periods. This reality justifies the use of a GARCH model to model the mean and volatility of RET.

Figure 1. Returns on the JSE All-Share Index (RET)

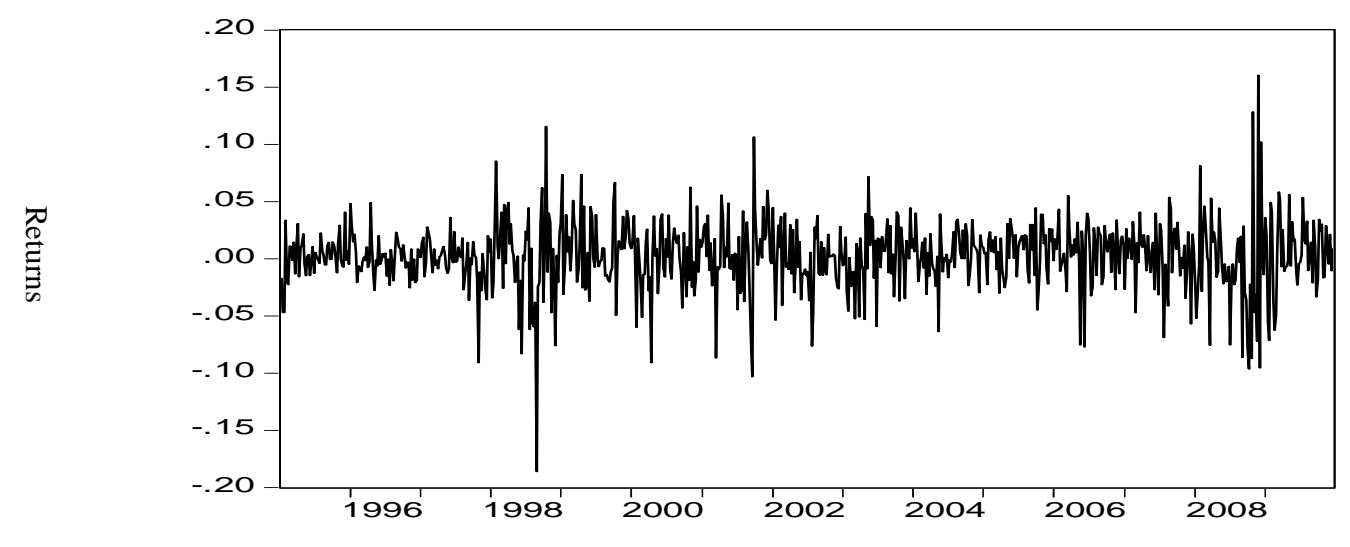

Moreover, the Lagrange Multiplier (LM) test rejects the null hypothesis of conditional homoscedasticity and confirms the presence of conditional heteroscedasticity in the series. The Dickey-Fuller generalised least squares (DF-GLS) test of the null hypothesis of unit root, not reported here, shows that the null hypothesis is rejected at the $1 \%$ level; thus RET is stationary.

Table 1 presents the results of the estimation of the time-varying $\operatorname{AR}(1)-\operatorname{GARCH}(1,1)$, as in Equations 4 and 5. 
Table 1 Estimation of the time-varying AR(1)-GARCH (1,1)

\begin{tabular}{|ll|}
\hline Parameter & Coefficient \\
$\alpha_{1}$ & 0.0091 \\
$\beta_{t}$ & $1.740^{* *}$ \\
$\phi_{0}$ & $0.000033^{*}$ \\
$\phi_{1}$ & $0.11724^{*}$ \\
$\phi_{2}$ & $0.8461^{*}$ \\
\hline
\end{tabular}

Note: $*$ and $* *$ mean significant at $1 \%$ and $5 \%$, respectively.

It is important to note that the estimation of the coefficient $\beta_{t}$, as reported in Table 1 , relates to its final state value. The time series of the estimated time-varying risk aversion is reported in Figure 2.

Figure 2 Estimated market time-varying risk aversion in South Africa

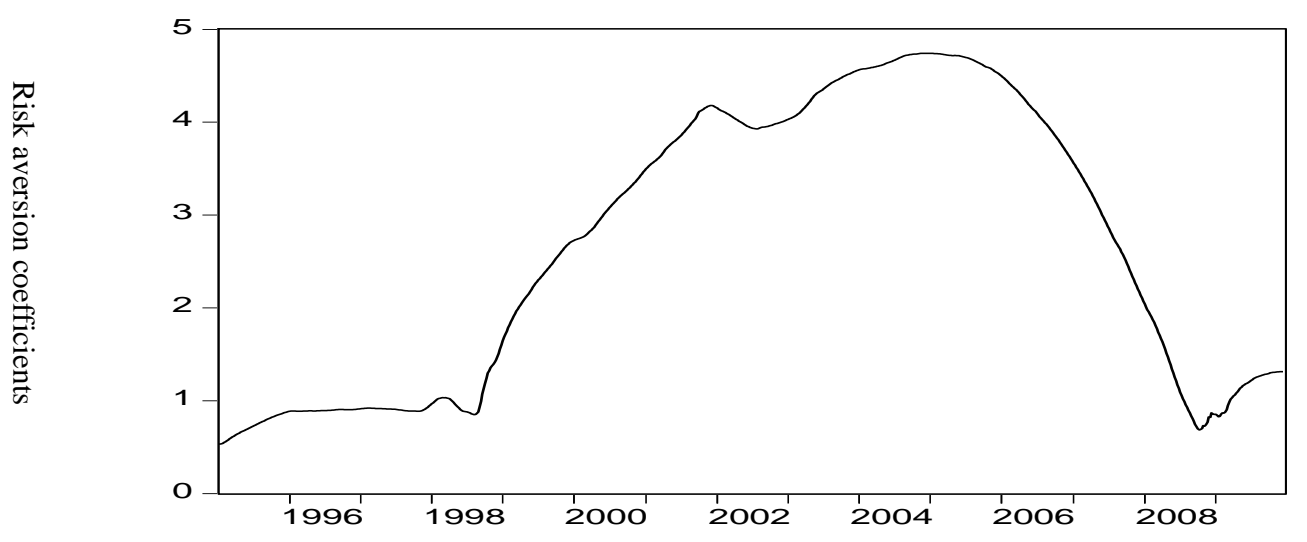

The results of the estimation of risk aversion show that its value varies between 0.7 and 4.7 in the period 1996 to 2009. More importantly, these results show significant variation in risk aversion in the periods 1998-2000, 2002-2004 and 2008. The cause of the changes in risk aversion in South Africa during these periods should be attributed to its vulnerability to global economic and financial shocks as well as to shocks affecting emerging market economies. For example, the cause of the change in risk aversion in the period 1998-2000 should be attributed to the Asian financial crisis, which started in July 1997, followed by the Russian financial crisis in August 1998 and later on by financial crises in Argentina and Turkey in 2000-2001. This reality indicates the degree of contagion from financial crises in emerging markets and its effect on risk premiums. The change in the degree of risk aversion in South Africa during the period 2002-2004, as shown in Figure 2, should be attributed to the political and economic crisis in South Africa's neighbour Zimbabwe. Pretorius and De Beer (2004) show that the political and economic crisis in Zimbabwe led to the deterioration of the South Africa currency, the rand, and also to capital outflow from South Africa as a result of an increasing risk averse attitude to South Africa. The change in risk aversion in late 2008 should be attributed to the recent global financial crisis. Due to the global financial crisis and thus increasing risk aversion in emerging markets, the JSE experienced a net withdrawal of close to $\$ 10$ billion dollars in the month of October 2008, which saw the JSE-Alsi decline by more than $12 \%$ in the same month. This shows that the degree of risk aversion in South Africa depends more on factors exogenous to the South African economy. 


\section{FORECASTING PERFORMANCE OF THE TIME-VARYING AND FIXED-PARAMETER GARCH-M}

While the time-varying GARCH-M model has provided an estimation of the risk aversion parameters that are found to be influenced by regional and global shocks to the South African financial market, it is still important to compare the performance of the time-varying GARCH-M model with the fixed-parameter GARCH-M model in predicting stock market returns in South Africa.

Weekly data from August 2009 to December 2009 were used to assess the out-of-sample forecast performance of the time-varying and fixed parameter $\mathrm{AR}(1)-\mathrm{GARCH}(1,1)-\mathrm{M}$ models in estimating risk aversion and modelling stock returns. The paper uses the root mean square error (RMSE) as the loss function to evaluate the accuracy of the forecasts generated by the two models in predicting stock returns. The RMSE is obtained as follows:

$$
\sqrt{\frac{1}{N} \sum_{t=1}^{n}\left(y_{t}-\hat{y}_{t}\right)^{2}}
$$

where $y_{t}$ and $y_{t}$ are the actual and predicted values of stock returns respectively, and $N$ is the total number of observations.

To test whether the forecasts of the two competing models are equally accurate in terms of this loss function, we use the Diebold-Mariano (DM) test for the significance of the difference between the RMSE obtained from the each of the forecasting models. The null hypothesis of the DM test is written as follows:

$$
d_{t}=E\left[g\left(e_{t}^{1}\right)-g\left(e_{t}^{2}\right)\right]=0
$$

where $e_{t}^{i}$ is the forecast error obtained from model $i$ and $g($.$) refers to a particular loss function. E($.) is the expectation operator. The DM uses the autocorrelation-corrected sample mean of $d_{t}$ to test for Equation 12 . The DM test statistic is calculated as follows:

$$
S=[\hat{V}(\bar{d})]^{-1 / 2} \bar{d}
$$

where $\bar{d}=\frac{1}{N} \sum_{t=1}^{n} d_{t} ; \hat{V}(\bar{d})=\frac{1}{N}\left[\hat{\gamma_{0}}+2 \sum_{k=1}^{h-1} \hat{\gamma_{k}}\right]$ and $\hat{\gamma_{k}}=\frac{1}{N} \sum_{t=k+1}^{n}\left(d_{t}-\bar{d}\right)\left(d_{t-k}-\bar{d}\right)$

It is important to note that $h$ refers to forecast horizon. Under the null hypothesis of equal forecast accuracy, $S$ is asymptotically normally distributed. For example, we reject the null hypothesis at the 5\% level if $|S| \succ 1.96$ (twosided hypothesis test).

Table 2 presents the DM test statistic ( $S$ ) as well as the RMSE for 1-, 2- and 3-week-ahead forecasts of the fixed parameter AR(1)-GARCH(1,1)-M model $\left(\mathrm{RMSE}_{1}\right)$ and time-varying parameter AR(1)-GARCH(1,1)-M model $\left(\mathrm{RMSE}_{2}\right)$ used to estimate risk aversion. Univariate models have been found useful in predicting stock returns on shorter forecast horizons (Kaul, 1996). This is the reason why this paper focuses on comparing the short-term forecast performance of the two models. 
Table 2 the DM test statistic and the root mean square errors of the two GARCH models

\begin{tabular}{|llll|}
\hline Out-of-sample forecast & RMSE $_{\mathbf{1}}$ & $\mathbf{R M S E}_{\mathbf{2}}$ & DM-statistic \\
& & & \\
1-week-ahead & 0.020232 & 0.00086 & 2.797495 \\
2-week-ahead & 0.020599 & 0.0008314 & 11.76582 \\
3-week-ahead & 0.019868 & 0.0008497 & 3.067361 \\
\hline
\end{tabular}

The results presented in Table 2 show that the null hypothesis of equal predictability by the model is rejected at $1 \%$ at least for the three forecast horizons. This indicates the better performance of the time-varying GARCH model in predicting stock market returns and estimating risk aversion in South Africa. This result should confirm the importance of using a time-varying econometric technique in estimating risk aversion in the context of the GARCH-M model.

\section{CONCLUSION}

This paper attempted to estimate the time series of risk aversion in South Africa. Use was made of the Kalman filter technique to estimate the coefficient of risk aversion from the GARCH-M model. The results of the paper show that this coefficient is time varying and its variation is influenced by factors exogenous to South Africa, such as emerging market financial crises as well as global financial crises. The findings show that the stock market in South Africa is vulnerable to external shocks. Moreover, the paper compares the forecast performance of the time-varying GARCH-M model with the fixed parameter GARCH-M model in predicting stock returns and estimating the coefficient of risk aversion in South Africa. To this end the paper finds that the time-varying GARCH-M model outperforms the fixed parameter GARCH-M model in predicting stock returns when short-term forecast horizons are used. This finding shows the importance of the time-varying model in modelling stock returns and estimating risk aversion in South Africa.

\section{AUTHOR INFORMATION}

Lumengo Bonga-Bonga is currently a professor and head of the department of Economics and Econometrics at the University of Johannesburg, South Africa. He specialises in the fields Financial economics, monetary economics and Public Economics

\section{REFERENCES}

1. Abdmoulah, W. (2010), Testing the Evolving Efficiency of Arab Stock Markets, International Review of Financial Analysis, 19: 25-34.

2. Ahn, S. And Shrestha, K. (2009), Estimation of market risk premium for Japan, Enterprise Risk Management, 1(1): 33-43.

3. Bali, T.G. and Engle, R.F. (2007), Investigating ICAPM with Dynamic Conditional Correlation. NYU working paper No. FIN-07-051.

4. Bodie, Z. and Merton, R.C. (2000), Finance, New Jersey: Prentice Hall.

5. Bonga-Bonga, L (2009), An assessment of the degree of South Africa's financial integration to the world economy, African Finance Journal, 11(2): 67-79.

6. Chan, K. C.; Karolyi, A. G. and Stulz, R. (1992), Global Financial Markets and the Risk Premium on U.S. Equity, Journal of Financial Economics , 32: 137-169.

7. Chen, J. ( 2003), Intertemporal CAPM and the cross-section of stock returns, Unpublished paper, 2003.

8. Chou, R. (1988), Volatility Persistence and Stock Valuations: Some Empirical Evidence using GARCH, Journal of Applied Econometrics, 3, , 279-94.

9. Das, S. and Sarkar, N. (2009), Is the relative risk aversion parameter constant over time? A multi-country study, Empirical Economics, 38(3): 605-617.

10. Engle, R. F., D. M. Lilien and R. P. Robins (1987), Estimating Time Varying Risk Premia in the Term Structure: The ARCH-M Model, Econometrica, 55: 391-407..

11. Fama, E.F. (1998), Determining the number of priced State variables in the ICAPM, The Journal of Financial and Quantitative Analysis, 33(2): 217-231. 
12. Frank, N. and Hesse, H. (2009). Financial spillover to emerging market during global financial crisis. IMF working paper, WP/09/104.

13. French, K. R.; Schwert, G. W. and Stambaugh, R. F. (1987), Expected Stock Returns and Volatility, Journal of Financial Economics, 19:3-29.

14. Grabel, I. (2003), Averting crisis? Assessing measures to manage financial integration in emerging economies, Cambridge journal of Economics, 27: 317-336.

15. Guo, H. (2006), Time-varying risk premia and the cross section of stock returns, Journal of Banking and Finance 30, 2087-2107.

16. HARVEY, A.C (1989), Forecasting, Structural time series models and the Kalman Filter, Cambridge: Cambridge University Press.

17. Jagannathan L. R., and Runkle D. (1993), On the Relation Between the Expected Value and the Volatility of the Nominal Excess Returns on Stocks, Journal of Finance, 48(5):1779-1801.

18. Kaul, G. (1996), Predictable components in Stock Returns, in GS. Maddala and CR Rao (eds), Handbook of statistics, 14, Amsterdam: Elsevier Science, 269 -96.

19. Kim, S.W. and Lee, B.S. (2008), Stock Returns, Asymmetric volatility, Risk Aversion and Business Cycle: Some evidence, Economic Enquiry, 46(2):131-148.

20. Li, Y. and Zhong, M. (2005), Consumption habit and international stock returns, Journal of Banking and finance, 29: 579-601

21. Melton R. (1980), On Estimating the Expected Return on the Market: An Exploratory Investigation, Journal of Financial Economics, 8: 323-361

22. Merton, R. C.(1973), An Intertemporal Capital Asset Pricing Model, Econometrica, 41(5 ): 867-887.

23. Pretorius, A and De Beer, J. (2004) "Contagion in Africa: South Africa and a Troubled Neighbour, Zimbabwe", Economic Modeling, 21(4): 703-715.

24. Salman, F. (2002), Risk-Returns-Volume in a Emerging Stock Market, Applied Economic Letters, 9: 54952.

25. Sharpe, W. F. (1964), Capital asset prices: A theory of market equilibrium under conditions of risk, Journal of Finance, 19 (3): 425-442.

26. Shin, J. (2005), Stock Returns and Volatiltiy in Emerging Markets, International Journal of Business and Economics, 4: 31-43

27. Tswamuno, D.T.; Pardee, S. and Wunnava, P.V. (2007), Financial Liberalisation and Economic Growth: Lessons from the South African Experience, Journal of Applied Economics, 4: 75-89

28. Zalewska-Mitura, A. and Hall, S. G. (1999), Examining the first stages of market performance: a test for evolving market efficiency, Economics Letters, 64: 1-12. 
NOTES 